\title{
Thin Cementitious Slabs reinforced with Stainless Steel Fibers
}

\author{
P.B. Sakthivel ${ }^{1}$, A. Jagannathan ${ }^{2}$ and R. Padmanaban ${ }^{3}$ \\ ${ }^{I}$ Professor, Department of Civil Engineering, Jerusalem College of Engineering, Chennai, India \\ ${ }^{2}$ Associate Professor, Department of Civil Engineering, Pondicherry Engineering College, Puducherry, India \\ ${ }^{3}$ M.E. (Construction Engineering and Management) Student, Department of Civil Engineering, \\ Jerusalem College of Engineering, Chennai, India
}

\begin{abstract}
This experimental research by the present authors is to determine the engineering properties such as compressive strength, split-tensile strength, mortar flexural strength and impact energy strength of Fiber Reinforced Cementitious Composite (FRCC) using a new non-corrosive reinforcing material, namely Stainless Steel (SS) fibers. For this purpose, reference specimens (cubes, cylinders and prisms) as well as FRCC slabs of size $250 \mathrm{~mm} X 250 \mathrm{~mm} X 25 \mathrm{~mm}$ thick were cast. The reinforcing SS fibers of $12.5 \mathrm{~mm}$ length with aspect ratio of 28 were used in discontinuous form, and the specimens were cast with varying proportions of SS fibers varying from $0.5 \%$ to $2.5 \%$ (to volume of specimens). The impact study was conducted on test specimens using a simple free-fall velocity method, using $1 \mathrm{~kg}$ steel ball, dropped from a height of $600 \mathrm{~mm}$ in a repeated manner and the number of blows received on initial and final cracks (on ultimate failure) were studied. The energy absorbed by the cementitious slabs (test specimens) reinforced with SS fibers has been compared with the control specimens cast with plain cement mortar (without fibers). In general, the results show that there is an increase in the compressive, split-tensile and mortar flexural strength and also the energy absorption capacity of specimens cast with fibrous mortar using SS fibers (0.5-2.5\%), when compared to specimens made of plain cement mortar. The initial and final crack widths (during ultimate failure) on the slabs were observed, and the Residual Impact Strength (IRS) Ratio of test and control specimens has been compared. The various applications of using thin, non-corrosive cementitious slabs are brought out in this study.
\end{abstract}

Keywords: Cement Matrix, Corrosion, Energy Absorption, Fibers, Impact

\section{Introduction}

The Fiber Reinforced Cement Composite (FRCC) has been widely used since the middle of 20th century [1] and currently recognized as one of the most-efficient and high-performing materials for construction of slab and wall systems, manhole covers, roads, pavements and industrial floors, pipeworks and tunnel lining, jacketing around columns [2]-[6]. This is because FRCC provides combined properties of interest to civil engineering applications which include strength, toughness, energy absorption, durability, corrosion resistance, water tightness, appearance and constructability [7]. FRCC are constructed as thin sections (about 10-25 mm thickness), and made up of fiber (randomly oriented and distributed within the volume of the composite) and the matrix (cast with cement mortar using proper sand-cement and water-cement ratios, and no coarse aggregates); and both the fiber and the matrix are assumed to work together, through bond, and provide the synergism needed to make an effective composite [7]. The role of fibers in cement mortar [8] is not only to overcome the traditional weakness of inorganic cements, namely poor tensile strength and brittleness [4] but also to improve the resistance to impact, blast, explosion and other forms of dynamic loads when large amounts of energy are suddenly imparted to the structure [9]-[14]. The research carried out in the last few decades has established that the addition of short and discrete fibers to plain concrete or cement mortar enhances its engineering properties like compressive, tensile and flexural strengths and also its toughness [15]. When fibers are added to cementitious composites, they also control the propagation of cracks and limit the crack widths [16]; fibers bridging a crack can absorb energy by deforming and/or pulling out, depending on their bond characteristics; and the total energy absorption capacity of a material is enhanced by the mechanism of increase in the path of the cracks during separation or improvement in the material's capability to deform [17]. In order to develop a better mechanical bond between the fiber and the matrix, the fiber can be modified along its length by roughening its surface or by inducing mechanical deformations; thus fibers can be smooth, indented, deformed, crimped, coiled, twisted, with end hooks, end paddles, end buttons, or other anchorage systems; in some fibers, the surface is etched or plasma treated to improve the bond at the microscopic level [7].

\section{Research Significance / Objectives}

Fibers enhance the strength and, more particularly, the toughness of brittle matrices by providing a crack arresting mechanism. In order to design cementitious composites with high toughness, there is a need to understand better the energy absorbing mechanisms it generates [17]. The cement matrices consist of paste and 
mortar, and most of the developments with fiber reinforced cementitious matrices involve use of Ordinary Portland Cement, and a wide variety of fibers that are used in cement based matrices include metallic fibers, polymeric fibers, mineral fibers and vegetable fibers [18]. The fibers are sold on weight basis in the open construction market, irrespective of the dimensional requirements; therefore, it is important to select fibers with such dimensions which give maximum degree of performance for a particular application [19] and accordingly the length and content of the fiber reinforcement should meet the strength and toughness requirements of the product [4].

As corrosion in cementitious composites has been raised in several studies, and the reinforcing fibers used in cementitious composites should be non-corrosive; and also one of the methods to overcome the problem of corrosion is to use materials such as stainless steel [20]-[21] which are not susceptible to corrosion [2],[3],[7],[21], this study makes an attempt to use stainless steel fibers as reinforcing material in cementitious composites. Many researchers have paid attention in the past few years on impact loading and carried out investigations to understand the behavior of cement based composites under impact [22] and found that the amount of impact strength for fiber reinforced cement-based matrices/composites significantly increases with inclusion of a higher amount of fiber [23]-[24]. Even though some of these studies have indicated that adding discontinuous short fibers to a cementitious matrix could bring significant improvement in properties such as tensile strength [25]-[26], compressive strength [23] and impact strength [27], this subject is not well understood and there is a need for detailed investigation of each type of fiber and publish the results [23]. More particularly, in the case of impact loads, the understanding remains largely qualitative, with little agreement over the exact magnitude of these improvements and mechanisms; arguably, the root cause of this lack of understanding is the absence of a standardized test technique for conducting impact tests on these cement-based materials [24]. In view of the research gap discussed here, this study takes a consolidated decision based on previous studies and recommends the simplest and easiest method of impact testing using free-fall velocity tests [28]. The main objective of this study is to find the energy absorption of cementitious slabs reinforced with Stainless Steel (SS) Fibers (called the "Test Specimens") and compare the values with "Control Specimens" cast with Plain Cement Mortar (without fibers); and discuss the results obtained.

\section{Experimentation}

Materials.

The ingredients used for casting the FRCC slab specimens are OPC 53 Grade, Penna-brand cement, with specific gravity of 3.14 and properties (conforming to IS 12269:1987 [29]); locally available river sand with specific gravity of 2.74, and passing through sieve (conforming to Zone II of IS 383:1970 [30] and IS 2386 (Part VII): 1963) [31]; Stainless Steel (SS) fibers (properties as given in Table 1); and fresh potable water, fit for construction purposes.

Table 1 lists the chemical and mechanical properties of Stainless Steel (SS) metal reinforcing fibers Grade - AISI 304 in size of $0.45 \mathrm{~mm}$ dia X $12.5 \mathrm{~mm}$ long (cold drawn type) that were used to cast fibrous cementitious specimens in this study. Since the SS fibers received by the manufacturer (properties as given in Table 1) were crimped type, the authors were very much interested in using SS fibers for the experimental work in as-it-is received state, and no attempt has been made to remove or modify the fiber surface finishes applied by the fiber manufacturers.

Table 1. Properties of Stainless Steel (SS) Fibers

\begin{tabular}{|l|l|}
\hline \multicolumn{2}{|l|}{ Chemical Composition (\%) } \\
\hline $\mathrm{C}$ & 0.023 \\
\hline $\mathrm{Mn}$ & 1.470 \\
\hline $\mathrm{Si}$ & 0.500 \\
\hline $\mathrm{Ni}$ & 8.050 \\
\hline $\mathrm{Cr}$ & 18.260 \\
\hline Mechanical Properties (of SS Crimped) \\
\hline Size/equivalent dia & $0.450 \mathrm{~mm}$ \\
\hline Length & $12.500 \mathrm{~mm}$ \\
\hline Aspect Ratio & 28 \\
\hline UTS & $1353 \mathrm{~N} / \mathrm{mm}^{2}$ \\
\hline
\end{tabular}

Casting of Specimens. For conducting the impact tests, a total of 18 cementitious slabs (of size 250 $\mathrm{mm}$ X $250 \mathrm{~mm}$ X $25 \mathrm{~mm}$ thickness) were cast in wooden moulds placed on a wooden platform. Out of these, 3 nos. are "Control Specimens" (cast with plain cement mortar without fibers) and 15 nos. are "Test Specimens" (cast with fibrous cement mortar using SS fibers of $0.5 \%, 1 \%, 1.5 \%, 2 \%$ and $2.5 \%$ of volume of specimens, and 3 specimens in these 5 categories). Reference specimens were also cast to determine the cube compressive strength using moulds of size $100 \mathrm{~mm} \mathrm{X} 100 \mathrm{~mm}$ X $100 \mathrm{~mm}$, cylinders for finding out the split tensile strength 
using moulds of $100 \mathrm{~mm}$ diameter X $200 \mathrm{~mm}$ height, and flexural strength with prism moulds of $40 \mathrm{~mm} \mathrm{X} 40$ $\mathrm{mm}$ X $160 \mathrm{~mm}$.

The wooden moulds were oiled, and the excess grease was wiped-off using a soft cloth while at wet state in order that the oil does not mix with the plain or fibrous cement mortar during casting of cementitious slabs; and after drying of the oil, the casting process of the cementitious slabs was commenced [32]. The cement mortar is prepared with sand-cement ratio of 2:1 and water-cement ratio of 0.43 in line with ACI codal provisions [3]. But there is no standard procedure that is adopted in preparing the fibrous cementitious mortar, but the ultimate aim is to prepare the fibrous mortar without any clustering of fibers at one location in cement mortar. The required quantity of cement, sand and stainless steel fibers are measured and kept ready for mixing, as shown in Fig.1. After preparation of dry fibrous mortar, the water is added, as shown in Fig.2. Here, the mixing of the fibrous mortar was done for more than a minute [33] in order to allow the fibers to get randomly distributed in the mortar [34], and finally a homogenous mixture with proper consistency is obtained, as shown in Fig.3. It is important to note here that water added to the dry fibrous mortar has been strictly as per the watercement ratio of 0.43 adopted for this project, and no additional water has been added [35]. Casting of specimens was done in wooden moulds, as shown in Fig. 4, and the test as well as control specimens have been allowed to set for minimum 24 hours and demoulded. The curing process is commenced immediately using a system of sprinkling fresh potable water on specimens wrapped in gunny sacks. Subsequently, the specimens are transferred to the curing tank; and after 28 days, the specimens are taken out and dried in the sun before being tested.

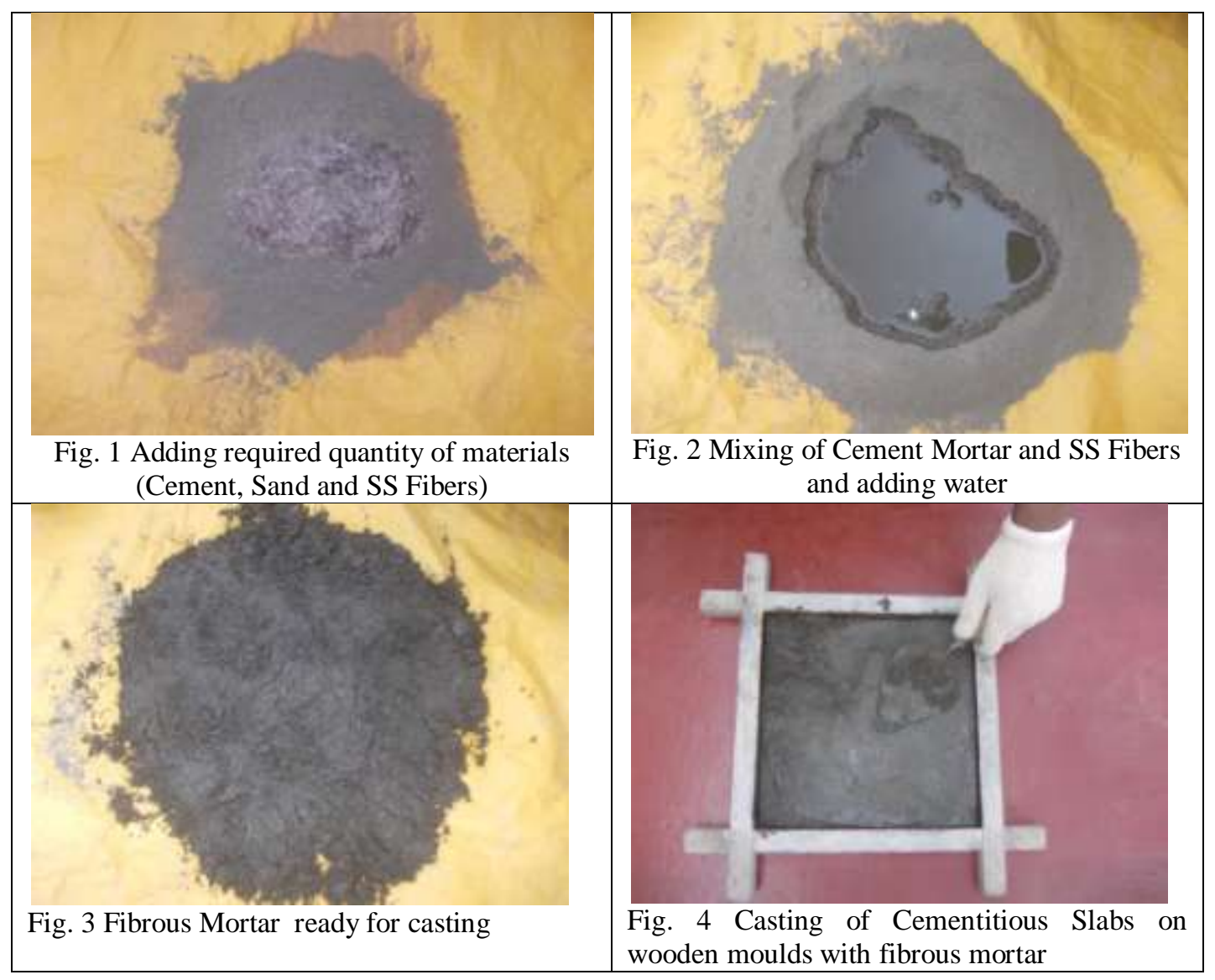

\section{Specimen Identification.}

The test and control specimens were white-washed prior to test to allow better visibility of the crack development [34]. All the slabs were given an unique identification number, for example, SS $12.5-0.5 \%$ (2) B (as shown in Fig.7a), SS 12.5 represents Stainless Steel fibers of $12.5 \mathrm{~mm}$ length, 0.5\%, the percentage of fibers to volume of specimens used, (2) indicates the specimen number 2, and B - the Bottom side of Specimen.

\section{Testing of Specimens.}

The cubes, cylinders and prism specimens were tested for compressive, split-tensile and mortar flexural strength respectively at 28 days and the results presented in Table 2 . The impact test was conducted on the test and control specimens after 28 days of curing using a drop weight set up, as per the procedure demonstrated in 
previous studies of Sakthivel et al., 2012 [21]; Anitha et al. (2012) [22]; Sakthivel and Jagannathan (2012a) [28]; and Sakthivel and Jagannathan (2012b) [32]. The drop weight was a steel mass of $1 \mathrm{~kg}$ and the mass has been dropped on to the slab in the centre from a predetermined height of $600 \mathrm{~mm}$. A rope and pulley arrangement with a pipe guide, which enables a central impact in the vertical direction, was used to manually lift the steel mass to the required height and repeatedly drop it on the specimen surface. The number of blows required to cause the first visible crack at bottom of the specimen was recorded as the first or initial crack. After the appearance of the first crack, the impact test was continued by dropping the steel mass till the ultimate failure stage has been achieved. At the time when final cracks were noticed, the impact loading exercise was stopped, and the total number of blows received are noted down; and this stage is treated as the ultimate failure stage of the specimen. The calculations of energy absorption at initial and final crack stages are given below.

\section{Energy Absorption}

The total energy absorbed by the cementitious composite slabs when struck by a steel mass depends on the local energy absorbed both in contact zone and by the steel mass (impactor), and the energy absorption is calculated from the following formula in equation (1) from the studies of Sakthivel et al., 2012 [21]; Anitha et al. (2012) [22]; Sakthivel and Jagannathan (2012a) [28]; and Sakthivel and Jagannathan (2012b) [32]:

$\mathrm{E}=\mathrm{n} \times(\mathrm{w} \times \mathrm{h})$ Joules

where $\mathrm{E}=$ energy (absorbed by the specimen on impact) in Joules

$\mathrm{n}=$ number of blows (on impact specimen)

$\mathrm{w}=$ weight (of steel mass) in Newton

$\mathrm{h}=$ height (from where steel mass is dropped on the specimen) in meter

In equation (1), constant values are $\mathrm{w}=9.81 \mathrm{~N}$ (weight of the ball) and $\mathrm{h}=0.6 \mathrm{~m}$ (height of fall), but the number of blows are based on the initial and final cracks. Table 3 gives the energy absorption capacities of slab specimens cast with plain cement mortar and fibrous mortar using SS fibers of 0.5 to $2.5 \%$.

\section{Results and Discussions}

\section{Strength Parameters of Plain and Fibrous Cement Mortar.}

From Table 2, it can be observed that the 28-day cube compressive strength has increased enormously (i.e., from $33 \mathrm{~N} / \mathrm{mm}^{2}$ to $53.12 \mathrm{~N} / \mathrm{mm}^{2}$ ) on increasing the SS fiber percentage from $0 \%$ to $2.5 \%$ respectively. When the SS fiber percentage is increased from $0 \%$ to $2.5 \%$, the split tensile strength at 28 days shows an corresponding increase, i.e., from $4.6 \mathrm{~N} / \mathrm{mm}^{2}$ to $8.81 \mathrm{~N} / \mathrm{mm}^{2}$. The prism mortar flexural strength at 28 days is also found to increase from $5.80 \mathrm{~N} / \mathrm{mm}^{2}$ to $7.92 \mathrm{~N} / \mathrm{mm}^{2}$ for an increase in SS fiber percentage from $0 \%$ to $2.5 \%$.

Table 2 Strength of Specimens of Cement Mortar (with Plain \& SS Fibers)

\begin{tabular}{|l|l|l|l|}
\hline $\begin{array}{l}\% \text { of SS Fibers } \\
\text { Used }\end{array}$ & $\begin{array}{l}\text { Cube Compressive Strength } \\
\text { at 28 days }\left(\mathrm{N} / \mathrm{mm}^{2}\right)\end{array}$ & $\begin{array}{l}\text { Split Tensile Strength } \\
\text { at 28 days }\left(\mathrm{N} / \mathrm{mm}^{2}\right)\end{array}$ & $\begin{array}{l}\text { Mortar Flexural Strength } \\
\text { at 28 days }\left(\mathrm{N} / \mathrm{mm}^{2}\right)\end{array}$ \\
\hline 0.0 & 33.00 & 4.60 & 5.80 \\
\hline 0.5 & 41.63 & 6.26 & 5.73 \\
\hline 1.0 & 47.17 & 7.32 & 6.74 \\
\hline 1.5 & 49.35 & 7.43 & 7.12 \\
\hline 2.0 & 50.25 & 8.49 & 7.63 \\
\hline 2.5 & 53.12 & 8.81 & 7.92 \\
\hline
\end{tabular}

From Table 3 and Fig. 5, it is seen that the energy absorption at first crack is 5.886 (for plain cement mortar) and increases from $11.772 \mathrm{~J}$ to $29.430 \mathrm{~J}$ for increase in SS fiber percentage from $0.5 \%$ to $2.5 \%$. The energy absorbed (at initial crack stage) by the cementitious slabs reinforced with SS 0.5\%, 1\%, $1.5 \%, 2 \%$ and $2.5 \%$ are $11.772 \mathrm{~J}, 11.772 \mathrm{~J}, 17.658 \mathrm{~J}, 23.544 \mathrm{~J}$ and $29.430 \mathrm{~J}$ respectively.

From Table 3 and Fig. 5, it is observed that for plain cementitious slabs (with $0 \%$ fibers), the ultimate failure has occurred after receiving energy absorption of $11.772 \mathrm{~J}$. For slabs cast with SS fiber percentage of $0.5 \%, 1 \%, 1.5 \%, 2 \%$ and $2.5 \%$, the energy absorbed by the slabs at ultimate failure stage is $23.544 \mathrm{~J}, 29.430 \mathrm{~J}$, $47.088 \mathrm{~J}, 64.746 \mathrm{~J}$ and $100.062 \mathrm{~J}$ respectively. On analyzing this, it can be inferred that the energy absorbed by the cementitious slabs with SS fibers of $0.5 \%, 1 \%, 1.5 \%, 2 \%$ and $2.5 \%$ is about 2 times, 2.5 times, 4 times, 5.5 times and 8.5 times (respectively) of the energy absorbed by plain cementitious slabs (without fibers).

From Table 3 and Fig. 5, it can also be inferred that for every 0.5\% increase in fiber percentage in FRCC slabs, i.e., there is an increase in energy absorption. This means that when the fiber percentage was increased from 0 to $0.5 \%, 0.5$ to $1 \%, 1 \%$ to $1.5 \%, 2 \%$ to $2.5 \%$, there is a jump in value of about 2 times (i.e., from $11.772 \mathrm{~J}$ to $23.544 \mathrm{~J}$ ), 1.25 times (i.e., from $23.544 \mathrm{~J}$ to $29.430 \mathrm{~J}$ ), 1.6 times (i.e., $29.430 \mathrm{~J}$ to $47.088 \mathrm{~J}$ ), 1.375 times (i.e., from $47.088 \mathrm{~J}$ to $64.746 \mathrm{~J}$ ), and about 1.54 times (i.e., from $64.746 \mathrm{~J}$ to $100.062 \mathrm{~J}$ ). Overall, it 
can be established from this study that as the percentage of SS fibers increases, there is a corresponding increase in energy absorption capacity of FRCC slabs.

Table 3. Energy Absorption and IRS Ratio of Cementitious Slabs (with and without SS Fibers)

\begin{tabular}{|c|c|c|c|c|c|}
\hline $\begin{array}{l}\text { Fiber } \\
\%\end{array}$ & First Crack & $\begin{array}{l}\text { Ultimate } \\
\text { Failure } \\
\text { (N) }\end{array}$ & $\begin{array}{l}\text { Energy Absorption at } \\
\text { first crack } \\
\text { based on equation (1) } \\
\text { (N) }\end{array}$ & $\begin{array}{l}\text { Energy Absorption at } \\
\text { Ultimate Failure } \\
\text { based on equation (1) } \\
\text { (N) }\end{array}$ & IRS Ratio \\
\hline & & & $\mathbf{A}$ & B & B/A \\
\hline 0.0 & 1 & 2 & 5.886 & 11.772 & 2.00 \\
\hline 0.5 & 2 & 4 & 11.772 & 23.544 & 2.00 \\
\hline 1.0 & 2 & 5 & 11.772 & 29.430 & 2.50 \\
\hline 1.5 & 3 & 8 & 17.658 & 47.088 & 2.67 \\
\hline 2.0 & 4 & 11 & 23.544 & 64.746 & 2.75 \\
\hline 2.5 & 5 & 17 & 29.430 & 100.062 & 3.40 \\
\hline
\end{tabular}

(Note: thickness of cementitious slab $=25 \mathrm{~mm}$, height of blow $=600 \mathrm{~mm}$, weight of steel mass $=1 \mathrm{~kg}$ )

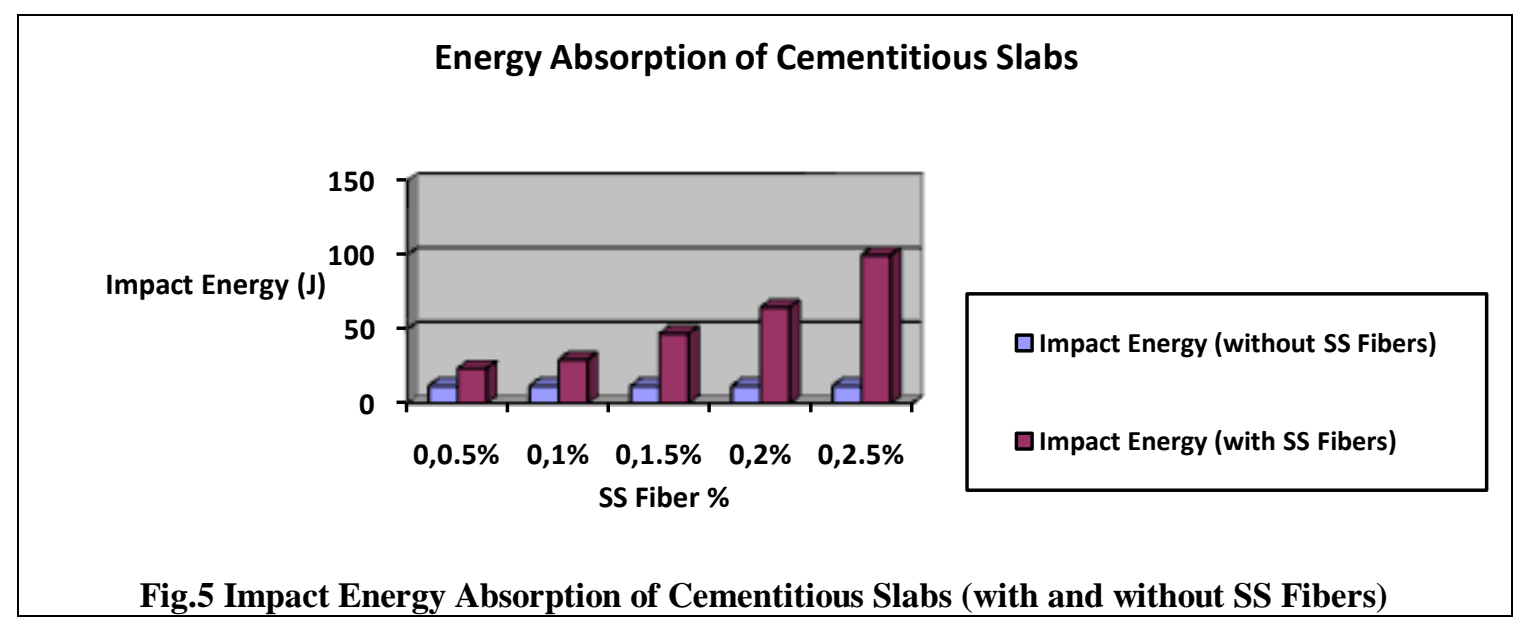

\section{Cracking Studies}

The crack-width of slabs subjected to impact load is given in Table 4. From Figs. 6a and 6b, it is observed that the crack-width could not be measured for cementitious slabs cast with plain cement mortar (without fibers) as the slab has broken into several pieces after taking little amount of impact energy. For cementitious slabs with SS fibers of $0.5 \%$, a brittle type of failure was noticed, and the cracks have propagated from bottom to the top of the slab, and the crack patterns are seen in Fig.7a (slab bottom view) and 7b (slab top view). From Table 4, it is also observed that when the SS fiber percentage in cementitious slabs is increased from $0.5 \%$ to $2.5 \%$, the initial crack-width has accordingly decreased from $0.25 \mathrm{~mm}$ to $0.10 \mathrm{~mm}$, and the final crack-width from $0.42 \mathrm{~mm}$ to $0.18 \mathrm{~mm}$ respectively. From the crack patterns observed in bottom side of slab, as seen from Figs.8a, 9a, 10a and 11a for slabs reinforced with the corresponding percentages of SS fibers of 1\%, $1.5 \%, 2 \%$ and $2.5 \%$, the crack width for each category is given in Table 4 , it can be concluded that the width of cracks reduce on increasing the percentage of fibers in the slabs. Figs. $8 \mathrm{~b}, 9 \mathrm{~b}, 10 \mathrm{~b}$ and $11 \mathrm{~b}$ shows the top view of the cementitious slabs (reinforced with SS fibers of 1\%, 1.5\%, 2\% and 2.5\% respectively) and cracks have not propagated from bottom to top at ultimate failure, and indicates that brittle failure has not occurred in the slabs.

Table 4 Crack Width of Cementitious Slabs subjected to Impact

\begin{tabular}{|l|l|l|}
\hline$\%$ of SS Fibers & Initial Crack Width $(\mathrm{mm})$ & Final Crack Width $(\mathrm{mm})$ \\
\hline $0.0 \%$ & -- & -- \\
\hline $0.5 \%$ & 0.25 & 0.42 \\
\hline $1.0 \%$ & 0.17 & 0.31 \\
\hline $1.5 \%$ & 0.15 & 0.28 \\
\hline $2.0 \%$ & 0.12 & 0.26 \\
\hline $2.5 \%$ & 0.10 & 0.18 \\
\hline
\end{tabular}




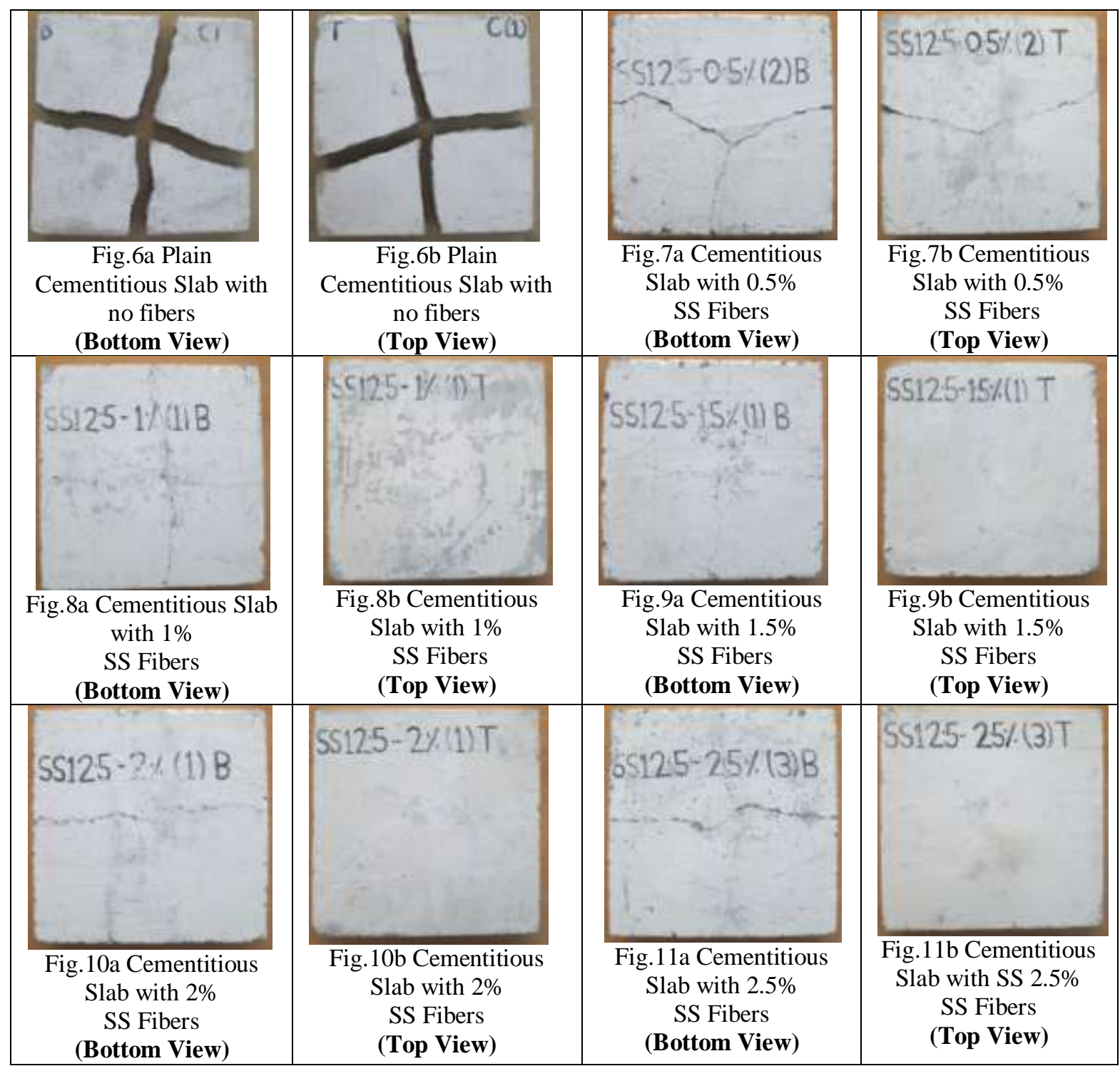

\section{Conclusion}

From the above studies, it can be concluded that the Stainless Steel reinforcing fibers are capable of increasing the strength parameters of cementitious matrix, and more importantly, the energy absorption capacity of cementitious slabs. Also, on increasing the fiber percentage from 0.5 to 2.5 , the crack width of slabs decreased substantially on subjecting the slabs to impact loading. Thus, Fiber reinforced cementitious composites can be recommended for a number of applications viz., prefabricated or precast thin slab elements and shell structures, thin structural elements/ facades designed for aesthetical purposes involving flexible shapes, and other facilities such as pavements, roads and industrial floors, and also as a repair and rehabilitation material. The authors recommend that flexure studies on Fiber Reinforced Cementitious Composites reinforced with Stainless Steel Fibers may be conducted by the researchers in the future, which will support this study to a great extent.

\section{Acknowledgements}

The present authors, Dr. P.B. Sakthivel, Dr. A. Jagannathan and Mr. R. Padmanaban thank the Managements of Jerusalem College of Engineering, Chennai, India and Pondicherry Engineering College, Puducherry, India for encouraging and providing facilities for conducting the experimental work relating to Thin Reinforced Cementitious Composites. The authors sincerely thank Mr. S.K. Doongaji, Director, Stewols India (P) Ltd., Uppalwadi, Nagpur-440 026, India for sponsoring the entire consumption of Stainless Steel fiber materials for this research work, and without whom this research work would not have been possible. 


\section{References}

[1] D. Homma, H. Adachi, Y. Iwahori, and N. Nishiwaki, Self Healing Capability of Fibre reinforced Cementitious Composites, Journal of Advanced Concrete Technology, 7(2), 2009, 217-228.

[2] A.E. Naaman, Ferrocement and Laminated Cementitious Composites (Ann Arbor, Michigan: Techno Press 3000, 2000). (8)

[3] ACI Committee 549, State of the Art Report on Ferrocement, ACI 549-R97, in Manual of Concrete Practice, American Concrete Institute, Farmington Hills, Michigan, 1997, 26 pages.

[4] Poděbradská, J., Pavlík, J., Toman, J., and Černý, R., Specific Heat Capacity of Cementitious Composites in High-Temperature Range, Proc. of Thermophysics, SAS Bratislava, 2003, 18-23.

[5] P.B. Sakthivel and A. Jagannathan, Ferrocement Construction technology and its Applications, Proc. of Int. Conf. on Structural Engineering, Construction and Management (ICSECM-2011), Kandy, Sri Lanka, 2011.

[6] A. Kar, I. Ray, A. Unnikrishnan, and J.F. Davalos, Microanalysis and optimization-based estimation of C-S-H contents of cementitious systems containing fly ash and silica fume, Cement \& Concrete Composites, 34, 2012, 419-429.

[7] A.E. Naaman, High Performance Fiber Reinforced Cement Composites: Classification and Applications, Proc. of International Workshop on Cement Based Materials \& Civil Infrastructure (CBM-CI), Karachi, Pakistan, 2007, pp.389-401.

[8] A. Cavdar, A study on the effects of high temperature on mechanical properties of fiber reinforced cementitious composites, Composites, 16(B), 2012, 2452-2463.

[9] A. Zielinski, H.W. Reinhardt, Stress-strain behavior of concrete and mortar at high rates of tensile loading, Cement and Concrete Research, 12, 1982, 309-319.

[10] W. Suaris, S.P. Shah, Properties of concrete and fiber reinforced concrete subjected to impact loading, American Society of Civil Engineers, Journal of the Structural Division, 109(ST7), 1983, 1717-1741.

[11] V Gopalratnam, S.P. Shah, Properties of steel fiber reinforced concrete subjected to impact loading, Journal of the American Concrete Institute, 83(1), 1986, 117-126.

[12] N. Banthia, S. Mindess, and A. Bentur, Impact behavior of concrete beams, Materials and Structures, 20(119), 1987, $293-302$.

[13] M.A. Glinicki, Toughness of fiber reinforced mortar at high tensile loading rates, ACI Materials Journal, 91(2), 1994, $161-166$.

[14] N. Banthia, S. Mindess, and J.F. Trottier, Impact resistance of steel fiber reinforced concrete, ACI Materials Journal, 93(5), 1996, 472-79.

[15] A.P. Singh, D. Singhal, Permeability of Steel Fibre Reinforced Concrete Influence of Fibre Parameters, Procedia Engineering, 14, 2011, 2823-2829.

[16] C.X. Qian, and P. Stroeven, Development of hybrid polypropylene-steel fibre-reinforced concrete, Cement Concrete Research, 30, 2000, 63-68.

[17] J.M. Alwan, A.E Naaman, and W. Hansen, Pull-Out Work of Steel Fibers from Cementitious Composites: Analytical Investigation, Cement \& Concrete Composites, 13, 1991, 247-255.

[18] R.D.T. Filho, K. Joseph, K. Ghavami and G.L. England, The use of sisal fiber as reinforcement in cement based composite, evista Brasileira de Engenharia Agricola e Ambiental, 3(2), 1999, 245-256.

[19] R. Hameed, A. Turatsinze, F. Duprat, and A. Selliar, Metallic Fiber Reinforced Concrete: Effect of Fiber Aspect Ratio on the Flexural Properties, ARPN Journal of Engineering and Applied Sciences, 4(5), 2009, 67-72.

[20] A. Jagannathan, Impact Study on Ferrocement Slabs reinforced with Polymer Mesh, Journal of Applied Engineering Research, http://www.thefreelibrary.com/Impact+study+on+ferrocement + slabs + reinforced + with + polymer + mesh. -a0216041365, 2008, 217228.

[21] P.B. Sakthivel, A. Jagannathan and R. Padmanaban, Influence Fibers on Impact Energy strength of Ferrocement Slabs reinforced with PVC-coated weld mesh, Proc. 28th National Convention of Civil Engineers and National Seminar on Role of Infrastructure for Sustainable Development, The Institution of Engineers (India), Roorkee, October 2012, 281-290.

[22] M. Anitha, R. Thenmozhi, and R. Deepa Shri, Behaviour of Hybrid ferrocement Slabs subjected to Impact, International Journal of Emerging trends in Engineering and Development, 4(2), 2012, 465-474.

[23] M.R. Nouri, J. Morshedian, Impact, Compressive and Flow Properties of fibre Reinforced Cementitious Composites, Iranian Journal of Polymer Science and Technology, 4(2), 1995, 134-140.

[24] N. Banthia, C. Yan, and K. Sakai, Impact Resistance of Fiber Reinforced Concrete at Subnormal Temperatures, Cement and Concrete Composites, 20, 1998, 393-404.

[25] S. Wang, A.E. Naaman, V.C. Li, Response of hybrid ferrocement plates with meshes and fibers, Journal of Ferrocement, 34(1), 2004, 275-288.

[26] M.A. Mansur, and P. Paramasivam, Cracking behavior and ultimate strength of ferrocement in flexure, Journal of Ferrocement, 16(4), 1986, 405-415.

[27] M. Gencoglu and B. Mobasher, Static and Impact Behavior of Fabric Reinforced Cement Composites in Flexure, RILEM Proc. on High Performance Fiber Reinforced Cement Composites (HPFRCC 5), France, 2007, 463-470.

[28] P.B. Sakthivel and A. Jagannathan, Study of PVC-coated Weld Mesh in Thin Reinforced Cementitious Matrix, Proc. of the 10th International Symposium on Ferrocement and Thin Reinforced Cement Composites (FERRO-10), Havana, Cuba, October 2012a, 17-27.

[29] IS 12269:1987, Specification for 53 Grade Ordinary Portland Cement, Bureau of Indian Standards, New Delhi, India, 1987.

[30] IS 383:1970, Specification for Coarse and Fine Aggregates from Natural Sources for Concrete, Bureau of Indian Standards, New Delhi, India, 1970.

[31] IS 2386 (Part-VII:1963) Reaffirmed 2002, Methods of Test for Aggregates for Concrete Part VII Alkali Aggregate Reactivity (Incorporating Amendment No.1), Bureau of Indian Standards, New Delhi, India, 1970.

[32] P.B. Sakthivel and A. Jagannathan, Corrosion-free Cementitious Composites for Sustainability, Proc. of the 37th Conference on Our World in Concrete \& Structures", Singapore, August 2012b, 361-371.

[33] Y. Wang, Tensile Properties of Synthetic Fiber Reinforced Mortar, Cement \& Concrete Composites, 12, 1990, 29-40.

[34] W.J.V. Lin and S.T. Quek, Behavior of Twisted Steel Fiber Reinforced Cementitious Composite, Proc. of the 32nd Conference on Our World in Concrete \& Structures", Singapore, August 2007.

[35] M.J. Shannag and T.B. Ziyyad, Flexural Response of Ferrocement with fibrous cementitious matrices", Construction and Building Materials, 16(4), 2007, 1198-1205. 